\title{
TERRITÓRIO, MÚSICA E DIFUSÃO DE INFORMAÇÕES: O CIRCUITO SONORO EM CAMPINAS-SP
}

Cristiano Nunes Alves*

Resumo: A problemática em torno da espessura do circuito de rádio FM e produção fonográfica em Campinas é o objetivo desta pesquisa. O circuito FM em Campinas entra decisivamente no campo da indústria cultural a partir da década de 1970, tendo se expandido concomitantemente ao circuito de produção fonográfica, num contexto de urbanização e metropolização crescentes no Brasil. Observamos que em contrapartida ao circuito FM, certa componente musical residual nos lugares movimenta, entre outros, a produção fonográfica alternativa e as rádios livres. Envolvidos por uma divisão técnica e territorial do trabalho dinamizada por círculos ascendentes de informação, esses circuitos residuais mais territorializados sobrevivem e por vezes se contrapõem à cisão e fragmentação urbanas. Trata-se, pois, de um estudo de Campinas enquanto um lugar que abriga em seu cotidiano densidades técnica, informacional e comunicacional. Interessa-nos apreender as condições geográficas contemporâneas de vida nesta cidade, indagando sobre seu componente comunicacional.

Palavras-chave: uso do território, comunicação, informação, música, urbanização.

\section{TERRITORY, MUSIC AND DISSEMINATION OF INFORMATION: THE SOUND CIRCUIT IN CAMPINAS-SP}

\begin{abstract}
This research examines the formation and the thickness of the circuits of radio FM and the music production in Campinas. The circuit FM in Campinas falls in the field of cultural industry since the decade of 1970, and has been expanding in the context of urbanization and metropolis growing in Brazil. Today this circuit incorporates a bigger system, coupled with the strategies of vertical use of the territory. We noticed that in contrast to the circuit FM, some residual musical component in places involves, among others, the alternative production and free radios. These circuits involved by a technically and territorial division of labor spurred by circuits upside of information, survive to the urban division and fragmentation. It is, therefore, a study of Campinas as a place that houses technical, informational and communicational densities. We analyzed geographical conditions of contemporary life in this city, inquiring about the communication component in the use of the territory.
\end{abstract}

Keywords: Use of the Territory, Communication, Information, Music, Urbanization.

\section{Introdução}

Hoje com cerca de 1.100 .000 habitantes, a cidade de Campinas é a terceira maior do estado de São Paulo. Sob a sua região, marcada pela desigualdade socioterritorial, incidem importantes elos informacionais, configurando um centro industrial e tecnológico com intensa ligação organizacional com a metrópole paulistana. 0 circuito fonográfico campineiro se originou a partir da década de 1950, enquanto a rádio FM se desenvolveu na década de 1970, no compasso do crescimento do mercado fonográfico nacional. Entendemos que por meio de uma catequese musical, se expandiu a influência no "circuito sonoro", noção para o conjunto de práticas territorializadas em torno da música, elemento de destaque na constituição do espaço urbano contemporâneo.

Trata-se de reconhecer que no contexto de urbanização acelerada do

*E-mail: geousp@usp.br. 
território brasileiro posiciona-se a centralidade das emissoras concessionadas de rádio FM na divulgação maciça da parcela mais rentável da produção fonográfica.

O movimento do circuito sonoro implica, de um lado, nas materialidades, com o uso dos fixos: casas com som ao vivo, lojas de disco, emissoras de rádio e ainda o uso dos mais diversos objetos técnicos - de aparelhos de rádio até televisores. Sua dinâmica abrange, por outro lado, a gravação da produção fonográfica, as mediações das experiências cotidianas ligadas à música e perpassa a produção musical, os eventos musicais bem como todo o conflitocooperação entre os agentes envolvidos.

Nesse artigo abordamos a estrutura da produção fonográfica e da radiodifusão FM em Campinas. Procuramos analisar a espessura da divisão territorial do trabalho presente no circuito sonoro em Campinas. Interessa-nos esse circuito enquanto meio difusor de informações no território. Indagamos sobre a articulação e a repartição de tarefas nas cidades, pois queremos os elementos de base para compreender as possibilidades de usos alternativos do território, dinamizáveis por meio das informações ascendentes, estas constituídas no lugar. ${ }^{1}$ Iniciando os trabalhos, apresentamos a problematização do tema do uso do território e da difusão de informações nos lugares. Em seguida expomos uma sistematização da empiria, apresentando parte de nossa cartografia e interpretação do

\footnotetext{
1 No inventário da produção fonográfica e da radiodifusão $\mathrm{FM}$ em Campinas, além do levantamento bibliográfico sobre a temática, realizamos uma série de trabalhos de campo. Reunimos dessa forma um importante "campo de informação primário" resultante de entrevistas com agentes do circuito sonoro e visitas a lugares conformados ou apropriados pelo circuito.
}

tema da música e da radiodifusão em Campinas.

\section{A proposta das densidades e o circuito sonoro: a esquizofonia embutida na dinâmica dos lugares}

Para o desenvolvimento desta pesquisa nos apoiamos, entre outros autores, na teoria do espaço geográfico proposta por M. Santos e, em particular, mobilizamos os conceitos de densidades comunicacional, técnica e informacional. Segundo Santos (1997, p. 257), são formas-conteúdo articuladoras dos lugares, "atributos que se interpenetram e cuja fusão os caracteriza e distingue". Procuramos, dessa maneira, encontrar um caminho para o exame do potencial comunicativo na cidade atual, preocupação central desse estudo. ${ }^{2}$

Conforme Santos (1997, p. 257), a densidade técnica "é dada pelos diversos graus de artifício", conferindo profundidade à divisão territorial do trabalho nos lugares. Para Santos e Silveira (2001, p. 279), no Brasil contemporâneo "há, em uma porção considerável do território uma maior densidade técnica acompanhada de maior densidade informacional". Observamos esse fato na cidade de Campinas, pois dotada das possibilidades informacionais do período em curso. Todavia, ponderam estes últimos autores, famílias de técnicas consideradas obsoletas podem ser também a base para produzir e difundir a informação no lugar, condição na qual a técnica traz consigo o

\footnotetext{
2 Trabalhamos sob a perspectiva de que a existência e o funcionamento de um circuito ganham significado quando abordadas as estratégias políticas no território usado, sinônimo de materialização e acontecer de objetos e ações no espaço geográfico (SANTOS, 1997).
} 
reverso e, assim, sua finalidade é alterada, ${ }^{3}$ mediatizando a comunicação com uma série de inovações nos lugares. ${ }^{4}$

Por sua vez, a densidade informacional, derivada em parte da densidade técnica, corresponde ao grau de abertura do lugar para entrar em contato com outros lugares, trazendo vantagens a determinados agentes e setores.

A propósito das variáveis informacionais, Schafer (1997, p. 133) afirma que, em virtude do afastamento dos sons de seus contextos originais, a partir do telégrafo, constituiu-se o fenômeno da esquizofonia que "refere-se ao rompimento entre um som original e sua transmissão ou reprodução eletroacústica." Os traços da inovação esquizofônica se inserem num conjunto maior de transformações de sistemas técnicos que, em seu conjunto, propõe G. Friedman (1968), constituem e impulsionam uma revolução no tempo livre, dispensando a presença humana para a ação e a transmissão de informações.

Alinhavando ainda nossa reflexão, ponderamos, a partir de Lefebvre (1969), Harvey (1992; 2003; 2006), Santos (1994a; 1997), Becker (1977) e Gorz (2005), que, mesmo diante da presença maciça de uma

\footnotetext{
${ }^{3}$ Poderiam tais pressupostos nos auxiliar no estudo da subversão dos objetos e funções técnicas no caso da apropriação das novas tecnologias da informação por um possível circuito informacional-comunicacional ascendente? No intuito de refletir sobre a questão, nos apoiamos, entre outros, nos estudos de Vicente (1996, 2001), Caldas (1995) e Frith (2004), que expõem o uso destas tecnologias na produção fonográfica no contexto de industrialização e drenagem dos micro-circuitos da música pelas grandes empresas de informação.

${ }^{4}$ T. Hägerstrand (1967) trata a inovação como um tipo especial de transição, maleável, cujas marcas são impressas na dimensão espaço-temporal, sendo necessário o estudo sistemático de sua difusão no território, composta por estratégias sucessivas de terriorialização.
}

constante de informação cultural média, é importante a força de agregação que contém - saber e a comunicação entre as pessoas nos lugares. Destaca-se, desse modo, a densidade comunicacional, diferente das densidades técnica e informacional, pois está mais ligada ao lugar, ao saber e ao cotidiano (SANTOS, 1997). Santos e Silveira (2001, p. 101) entendem que o trabalho comum no lugar, a partir da densidade comunicacional, é um dado transformador na medida em que revela "interesses comuns que podem conduzir a uma consciência política."

A informação e a comunicação têm capacidade de ordenação social, e assim guardam "uma função política no sentido da constituição ou formação da polis" (SODRÉ, 1976, p. 19), ou seja, são entes de fundamental importância no contexto urbano contemporâneo. Daí a nossa inquietude com relação ao papel da informação e da comunicação na cidade contemporânea.

\section{O fenômeno esquizofônico em Campinas: o circuito sonoro ao longo do tempo}

Em virtude do afastamento dos sons de seus contextos originais, a partir do telégrafo, explica Schafer (1997, p. 133), constituiu-se o fenômeno da esquizofonia que "refere-se ao rompimento entre um som original e sua transmissão ou reprodução eletroacústica". A vida urbano-industrial e todo o alastramento das próteses no território que lhe é característica, desde então, cria lugares ruidosos, impregnando o meio sonoro com o traço de um novo período, esquizofônico. No estudo dos sistemas técnicos no circuito sonoro ao longo do tempo, lançamos mão do recurso a periodização (SANTOS, 1997). Santos e não 
de Silveira. Entender o funcionamento desse circuito nos remete às continuidades $\mathrm{e}$ descontinuidades territorializadas no tempo, a partir dos sistemas de eventos nos lugares. Os processos relacionados à temática indicam que Campinas, desde a chegada do fenômeno esquizofônico, dispõe de uma base técnica adequada à disseminação do componente informacional (MARIANO, 1972; GEIGER, 1963).

Na década de 1940, diante de um impulso a urbanização brasileira, a indústria cultural serve-se dos primeiros macrossistemas técnicos de informação (SANTOS, 1994b; ORTIZ, 2001) e a radiodifusão assume posição estratégica no agenciamento ideológico da nação (SODRÉ, 1999). Destaca-se como marco normativo, o surgimento do Código Brasileiro de telecomunicações em 1962, documento que cristaliza o poder já estabelecido em torno dos meios de informação de massa (ORTRIWANO, 1985).

Na década de 1970, dois eventos são de extrema importância para que se compreenda a situação atual das rádios FM: no contexto de crescimento do mercado fonográfico no Brasil, surge o Plano de FM, aplicado pelo governo militar, e funda-se a primeira FM de Campinas, a Rádio Andorinhas. Nessa época, se constitui o sistema aberto na produção fonográfica, que compreende uma estratégia de reestruturação produtiva do setor no qual o objetivo central das grandes gravadoras se desloca do controle da produção em si, agora pulverizada e barateada, para o controle da divulgação e distribuição dos fonogramas, tornando os pequenos selos prospectores de mercado (MORELLI, 1998; VICENTE, 1996; 2001).
Para viabilizar o milagre econômico foi necessário ao Estado e às grandes multinacionais da cultura, aprimorar o controle dos territórios a partir das consciências (MATELLART, 1976). Trata-se da criação de uma psicoesfera ${ }^{5}$ (SANTOS, 1997), de conformismo e adequação ao do poder instalado.

O processo de enquadramento do circuito sonoro, ganha contornos mais bem definidos, a partir dos anos 1990. Desde então, o circuito sonoro se adensa envolvendo toda a rede urbana brasileira, com destaque para Campinas.

\section{Análise geográfica da radiodifusão: 0 circuito de rádio FM em Campinas}

Os estudos sobre a evolução rede urbana brasileira (GEIGER, 1963) mostram que no meio esquizofônico a relação entre proximidade e distância se mostra cada vez mais uma variável administrada, produtora e produzida por um comando remoto de poder. Ocorrem importantes elos corporativos, ${ }^{6}$ que em diversos casos constituem e explicam as relações de interdependência entre os lugares.

Neste sentido, Pred (1979) trabalha o conceito de um sistema de cidades, um sistema social complexo formado por um

\footnotetext{
5 Para Santos (1997, p. 256), indissociada do mundo material da tecnoesfera, a psicoesfera seria - mundo das idéias, das crenças, "o lugar da produção de um sentido", que tanto estimula o imaginário quanto fornece regras a racionalidade.

6 Tais elos corporativos, se manifestam de inúmeros modos, seja numa rede de rádio $F M$, como a Jovem Pan e a retransmissão de seus conteúdos a partir de São Paulo por parte de um sistema de emissoras filiadas, ou mesmo na concentração regional de estúdios fonográficos e indústrias de tecnologia em Campinas.
} 
conjunto de cidades, seja ele regional ou nacional. Nesse sistema, por meio dos fluxos de informação as mudanças em um lugar implicam num corpo de mudanças alhures. Por sua vez, Raffestin (1993) assinala que a informação encontra na capital um território de controle, de chegada e de partida para si. De acordo com Santos (1997), o acontecer dos lugares pode ser estudado a partir dos elementos relacionados à espessura dos contatos e transmissões de informação. ${ }^{7}$

O circuito de FM é um retrato do modo como os grandes grupos de informação produzem hierarquicamente uma série de escalas e usam o território. ${ }^{8}$ No Quadro 1, destacamos a densidade normativa embutida na produção de escalas a partir da radiodifusão baseada no sistema de concessões.

\section{Campinas abriga atualmente} dezesseis emissoras concessionadas, ligadas a 12 grupos de informação, exceto a Rádio Educativa, pertencente à Prefeitura Municipal. Nove emissoras de FM são, na verdade, concessões outorgadas a outros municípios, redirecionadas a partir da cidade de Campinas.

\section{O circuito FM de Campinas (2008) - Concessões de $F M$ redirecionadas à Campinas}

Dez emissoras operam em rede e seis transmitem conteúdos a partir de Campinas, município de considerável densidade de sinais de rádio FM (Figura 1). A topologia das torres de transmissão e abrangência relacionadas indicam a sobreposição de canais e uma grande espessura técnica informacional sobre Campinas advindas do meio rádio.

Assim, além da Educativa, direcionada ao segmento adulto, outras cinco programações são produzidas localmente: Laser, Cidade e Líder atuam no segmento popular, enquanto Educadora e 89 FM são direcionadas ao público jovem.

Predomina a ação em rede no circuito de rádio. Tais redes são controladas por grandes grupos de informação, transmissores de conteúdos e/ou detentores de emissoras. Dados de 2007 indicam que 23 emissoras do dial de Campinas (conjunto de canais recebidos em território campineiro, composto por cerca de sessenta canais) são elos para difusão de diversas redes de rádio do país (Figura 2), retransmitindo conteúdos de programação.

\footnotetext{
7 Em nossa abordagem do circuito de FM, destacamos a densidade informacional em torno da difusão. Apoiamo-nos num conjunto de autores que tratam da radiodifusão em diversos domínios das ciências humanas: Amayo (1992), Lucca (2002) e Salgado (1941), entre outros.

8 Entre as várias implicações territoriais da radiodifusão, há o fato de a publicidade ter um valor relacionado ao potencial de mercado de cada um dos lugares. Desse modo, um anúncio de 30 segundos custa R\$12 em Barra Bonita, R\$100 em Campinas, R\$ 1.700 em São Paulo e R\$5.600 em toda a rede urbana 5.600 . Vê-se a produção de escalas no território a partir da radiodifusão.
} 
Quadro 1 - O circuito de rádio em Campinas

\begin{tabular}{|c|c|c|c|c|c|c|c|c|c|}
\hline \multicolumn{10}{|c|}{ O CIRCUITO DE RÁDIO FM DE CAMPINAS: ASPECTOS PRODUTIVOS DA EMPRESA - SISTEMAS TECNICOS ACIONADOS } \\
\hline \multicolumn{7}{|c|}{ Mercado e densidade normativa } & \multicolumn{3}{|c|}{ Fixos e trabalho (formas e funçóes) } \\
\hline \multirow{2}{*}{$\begin{array}{l}\text { Empresa } \\
\text { Rede } \\
\text { Proprietário }\end{array}$} & \multirow{2}{*}{\begin{tabular}{c|} 
Emissora \\
Frequêência $M h z$
\end{tabular}} & \multirow{2}{*}{$\begin{array}{l}\text { Aspectos da rede } \\
\text { Origem da programação }\end{array}$} & \multirow{2}{*}{ 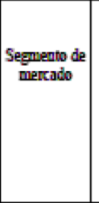 } & \multirow{2}{*}{$\begin{array}{l}\text { Origem da } \\
\text { concessão }\end{array}$} & \multicolumn{2}{|c|}{ Alcance da difusão } & \multirow{2}{*}{$\begin{array}{c}\text { Torre de } \\
\text { transmissão }\end{array}$} & \multirow{2}{*}{$\begin{array}{l}\text { Estrutura da emissora em campinas (composição } \\
\text { interna da empresa: departamentos, estrídios e } \\
\text { aspectos do fixo) }\end{array}$} & \multirow{2}{*}{ 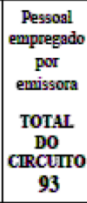 } \\
\hline & & & & & \begin{tabular}{|c|}
$\begin{array}{c}\text { Classe } \\
\text { de } \\
\text { potência }\end{array}$ \\
\end{tabular} & $\begin{array}{l}\text { (Abrangênci } \\
\text { a téórica em } \\
\text { quilômetros) }\end{array}$ & & & \\
\hline \multirow{3}{*}{$\begin{array}{ll}\text { Grupo } & \text { Cidade- } \\
\text { Laser } & \text { (Odilon } \\
\text { Garcia) } & \end{array}$} & CIDADE 92.5 & Transmissâo a partir de Campinas & Popular & Campinas-SP & A 1 & 40 & Campinas-SP & \multirow[t]{2}{*}{$\begin{array}{l}\text { - Toda estrutura da emissora. } \\
\text { - Mesmo prédio para as três emissoras } \\
\text { do grupo, no Jardim São Gabriel. }\end{array}$} & \multirow{3}{*}{9} \\
\hline & LASER 93.3 & Transmissão a partir de Campinas & Popular & Valinhos-SP & A 1 & 40 & Campinas-SP & & \\
\hline & MIX 97.5 & $\begin{array}{l}\text { Retransmisâo da cidade de São } \\
\text { Paulo (inserção de anuncios } \\
\text { locais) }\end{array}$ & Jovem & Itt-SP & A 1 & 40 & Itupeva-SP & \begin{tabular}{|l} 
- Departamento comercial \\
- Estudio para spots
\end{tabular} & \\
\hline \multirow{3}{*}{$\begin{array}{l}\text { Grupo } \\
\text { Comunicações } \\
\text { Brasil SAT }\end{array}$} & KISS 107.9 & $\begin{array}{l}\text { Retransmisão da cidade de } \\
\text { Cosmópolis (inserção de anúncios } \\
\text { regionais) }\end{array}$ & Jovem & $\begin{array}{l}\text { Cosmópolis- } \\
\text { SP }\end{array}$ & $\mathrm{C}$ & 7 & Cosmópolis-SP & \multirow{3}{*}{$\begin{array}{l}\text { - Departamento comercial } \\
\text { - Estúdio para spots } \\
\text { - Mesmo prédio no centro para as três emissoras do } \\
\text { grupo e o canal } 36 \text { de TV UHF, desde } 2004 .\end{array}$} & \multirow{3}{*}{7} \\
\hline & TUPI 96.5 & $\begin{array}{l}\text { Retransmisão da cidade de São } \\
\text { Paulo (inserção de anúncios } \\
\text { regionais) }\end{array}$ & Popular & \begin{tabular}{|l|} 
Santo \\
Antômio de \\
Posse-SP
\end{tabular} & B 1 & 16 & $\begin{array}{l}\text { Santo Antônio } \\
\text { de Posse-SP }\end{array}$ & & \\
\hline & SCALLA 96.9 & $\begin{array}{l}\text { Retransmisâo da cidade de São } \\
\text { Paulo (inserçẫo de anúncios } \\
\text { locais). }\end{array}$ & Adulto & $\begin{array}{l}\text { Hortolândia- } \\
\text { SP }\end{array}$ & $\mathrm{C}$ & 7 & Hortolândia-SP & & \\
\hline $\begin{array}{|lrr|}\text { Grupo } & \text { Nova } & - \\
\text { Rede } & \text { Central } & \text { de } \\
\text { Comunicações } & \\
\text { (Orestes Quércia) }\end{array}$ & $\begin{array}{l}\text { NOVA BRASIL } \\
103.7\end{array}$ & $\begin{array}{l}\text { Retransmissão do conteúdo da } \\
\text { Rede Nova (via satelite) }\end{array}$ & Adulto & Campinas-SP & A 1 & 40 & Campinas-SP & $\begin{array}{l}\text { - Estídio para spots, no mesmo prédio da Rádio } \\
\text { Central AM } 870 \mathrm{Khz} \text {, no Jardim Leonor. }\end{array}$ & 1 \\
\hline $\begin{array}{l}\text { Rede Aleluia } \\
\text { (arrendada junto a } \\
\text { Natal Gale) }\end{array}$ & MORENA 100.3 & $\begin{array}{l}\text { Retransmissão do conteúdo da } \\
\text { Rede Aleluia } \\
\text { (inserção de anúncios e pregações } \\
\text { locais) }\end{array}$ & Religioso & Campinas-SP & A 2 & 36 & Campinas-SP & $\begin{array}{l}\text { - Toda estrutura da emissora no mesmo prédio da } \\
\text { Rádio Jequatibá AM } 1230 \mathrm{Khz} \text { no Jardim } \\
\text { Chapadâo. }\end{array}$ & 8 \\
\hline Grupo Antena 1 & ANTENA 1107.5 & $\begin{array}{l}\text { Retransmissão do conteúdo da } \\
\text { Rede Via Satélite Antena 1 } \\
\text { (inserção de anúncios locais) }\end{array}$ & Adulto & Indaiatuba-SP & A 1 & 40 & Campinas-SP & - Departamento comercial no Bairro Cambui. & 10 \\
\hline $\begin{array}{l}\text { Rede } \\
\text { Metropolitana }\end{array}$ & LÍDER 105.5 & \begin{tabular}{|l|} 
Transmissão a partir de Campinas \\
(Emissora vinculada ìr Rede \\
Metropolitana, porém sema retransmissẫo \\
de conteúdo de programaçăo)
\end{tabular} & Popular & Sumaré-SP & B 2 & 12 & Sumaré-SP & - Toda estrutura da emissora no Bairro Castelo. & 8 \\
\hline \begin{tabular}{|l} 
Grupo \\
Bandeirantes
\end{tabular} & $\begin{array}{l}\text { EDUCADORA } \\
91.7\end{array}$ & Transmissão a partir de Campinas. & Jovem & Campinas-SP & A 1 & 40 & Campinas-SP & $\begin{array}{l}\text { - Toda estrutura da emissora. } \\
\text { - Prédio do Complexo da Rede Bandeirantes no } \\
\text { Jardim São Gabriel }\end{array}$ & 15 \\
\hline Rede Jovem Pan & \begin{tabular}{|l} 
JOVEM \\
89.9
\end{tabular} & $\begin{array}{l}\text { Retransmissão do conteúdo da } \\
\text { Rede Jovem Pan } \\
\text { (inserção de anúncios locais) }\end{array}$ & Jovem & $\begin{array}{l}\text { Águas de } \\
\text { Lindóia-SP }\end{array}$ & B 1 & 16 & Serra Negra-SP & - Departamento comercial no Jardim Flamboyant. & 3 \\
\hline Grupo Alpha & 89 FM 89.3 & Transmissão a partir Campinas & Jovem & Amparo-SP & A 4 & 24 & Campinas-SP & - Toda estrutura da emissora no Jardim Chapadão. & 18 \\
\hline Rede Globo & CBN 99.1 & $\begin{array}{l}\text { Retransmissão do conteúdo da } \\
\text { Rede CBN de noticias Parcela da } \\
\text { programação transmitida a partir } \\
\text { de Campinas }\end{array}$ & $\begin{array}{l}\text { Adulto } \\
\text { (noticias) }\end{array}$ & Campinas-SP & A 3 & 31 & Campinas-SP & $\begin{array}{l}\text { - Toda estrutura da emissora no mesmo prédio da } \\
\text { Rádio Brasil AM } 1270 \mathrm{Khz} \text {, no centro da cidade. }\end{array}$ & $\begin{array}{l}\text { Seen } \\
\text { informascão }\end{array}$ \\
\hline \begin{tabular}{|l|} 
Rede \\
Evangelica \\
Maranatha
\end{tabular} & $\begin{array}{l}\text { MARANATA } \\
106.1\end{array}$ & $\begin{array}{l}\text { Retransmissão do conteúdo da } \\
\text { Rede Maranatha. Parcela da } \\
\text { programação transmitida a partir } \\
\text { de Campinas }\end{array}$ & Religioso & Campinas-SP & B 2 & 12 & Campinas-SP & $\begin{array}{l}\text { - Estúdio de transmissão, numa casa no Jardim } \\
\text { Itatiaia }\end{array}$ & 4 \\
\hline \begin{tabular}{|l} 
Prefeitura \\
Muncipal \\
Campinas
\end{tabular} & $\begin{array}{l}\text { RÁDIO } \\
\text { EDUCATIVA } \\
101.9\end{array}$ & Transmissão a partir de Campinas & Adulto & Campinas-SP & B1 & 16 & Campinas-SP & $\begin{array}{l}\text { - Toda estrutura da emissora. } \\
\text { - Estúdio de transmissão na Torre do Castelo }\end{array}$ & 10 \\
\hline
\end{tabular}


Figura 1 - O circuito FM de Campinas (2008) - Concessões de FM redirecionadas a Campinas

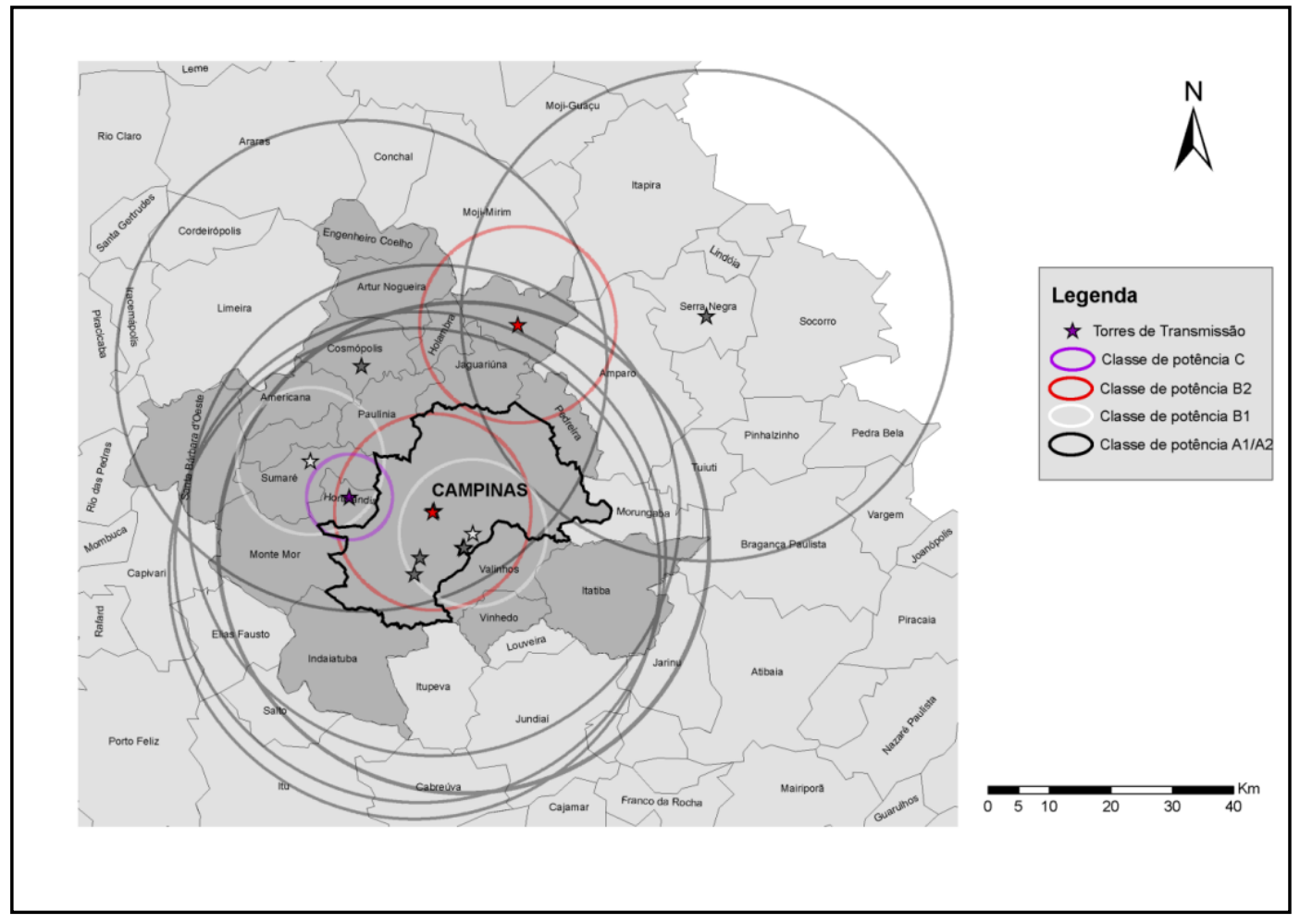

Elaboração: Cristiano Nunes Alves. Cartografia: Daniel Henrique Cândido.

Figura 2

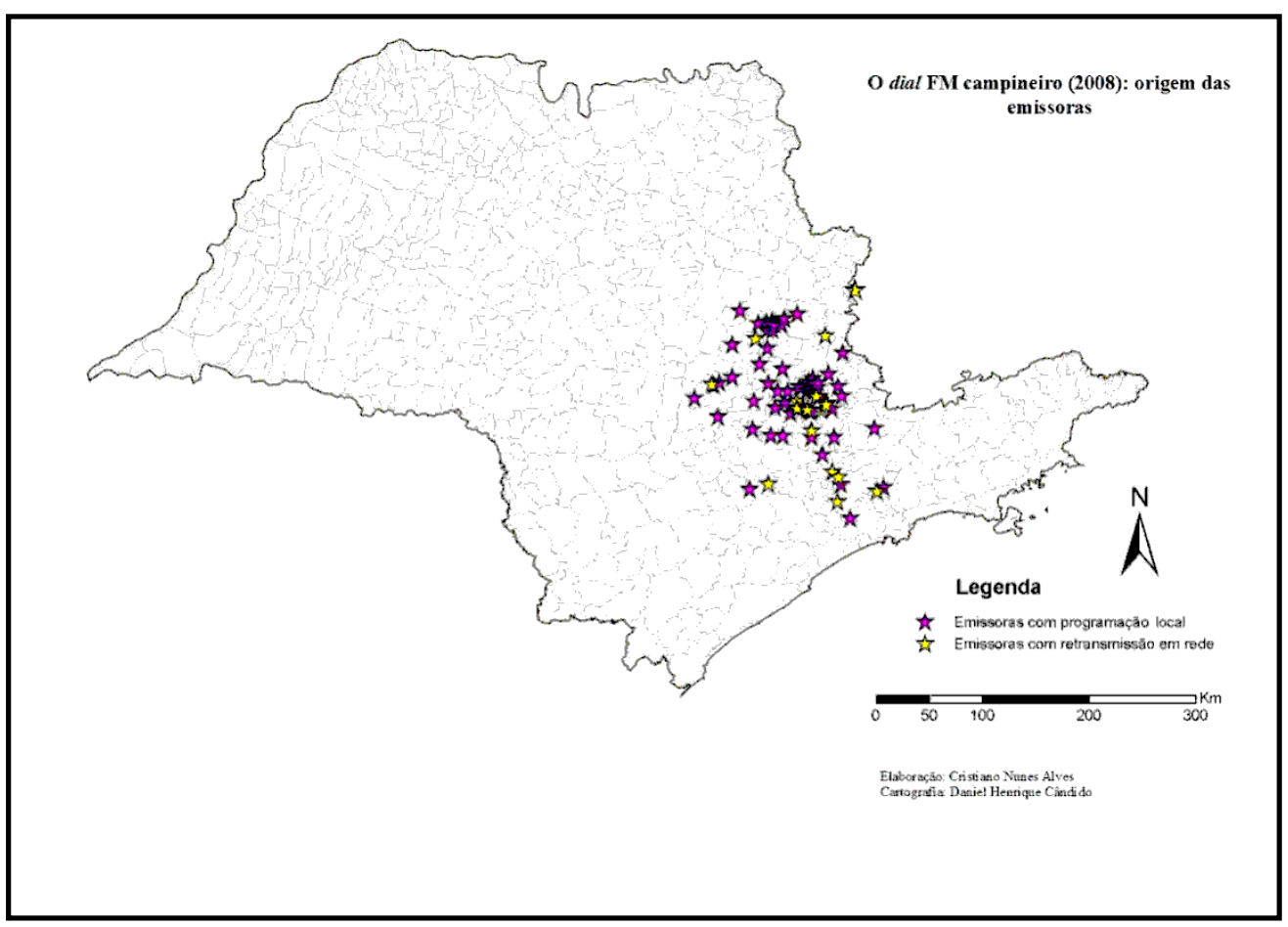


O produto musical local pouco se insere na programação das emissoras concessionadas, menos ainda a produção alternativa ao repertório médio. Já não é novidade que praticamente todas as emissoras concessionadas estão comprometidas com o grande mercado por meio da publicidade, inclusive concorrendo com os estúdios, fornecendo serviços de fonogramas publicitários, processo atrelado a vinculação de um repertório médio durante a programação, fundamentada em padrões musicais (LUCCA, 2002).

\section{A cidade e a produção fonográfica: da música aos circuitos da economia urbana}

Segundo Claire (2006, p. 21), ao geógrafo interessa entender a música e suas localizações, reais e ideais. Carney (1990), Neto (2004) e Romagnan (2000) destacam, ainda nesse viés, a pertinência do estudo da repartição e da difusão das atividades sonoras e musicais no território, enquanto Chaudoir (2003) defende o estudo da diversificação e da hierarquia dos fatos sonoros na cidade. ${ }^{9}$

Abordamos a espessura da divisão territorial do trabalho presente na produção fonográfica na cidade de Campinas-SP. Aqui, interessa-nos o circuito sonoro enquanto meio difusor de informações. Indagamos sobre o modo como tal repartição de tarefas no território se articula ou não com a indústria cultural, pois queremos chegar aos elementos de base para compreendermos as

\footnotetext{
${ }^{9}$ Destacamos ainda os estudos geográficos sobre a música de Pailhé (1998), Brennetot (2004) e Raibaud (2006). A partir da análise de diversas realidades, essas obras suscitam uma série de reflexões e propõem uma cartografia musical, úteis nesta análise e interpretação do circuito sonoro.
}

possibilidades de comunicação constituídas no lugar.

Grosso modo nos últimos 20 anos aprofunda-se a divisão técnica e territorial do trabalho em torno dos estúdios fonográficos em Campinas, diferente de um primeiro momento que perdura até a década de 1980, no qual o mercado era dividido entre alguns poucos estúdios locais.

Mas, foi partir da década de 1990 que 39 dos 51 estúdios inventariados foram instalados em Campinas. ${ }^{10}$ Sistematizamos informações a respeito de 27 estúdios de gravação, em funcionamento na cidade de Campinas no ano de 2008. Praticamente todos os estúdios se localizam no centro e nos seus arredores, em bairros predominantemente de classe média e classe alta. Os bairros Taquaral, Jardim Chapadão, Jardim Guanabara, Bosque, Cambuí, Nova Campinas e a área central concentram 24 estúdios. O levantamento feito aponta que dois estúdios são móveis e realizam serviços de gravação no lugar em que forem requisitados (Figura 3 ).

Ao longo de todo o nosso trabalho de campo estivemos atentos sobre a existência de estúdios de gravação nas periferias da cidade. Tivemos apenas indícios de alguns trabalhos em estágio preliminar utilizando em

\footnotetext{
${ }^{10}$ Fomos informados, sem maior detalhamento, da instalação de outros 21 estúdios em Campinas, além dos inventariados, todos surgidos grosso modo nos últimos dez anos, alguns já fechados. Trata-se de estúdios menores, em sua maioria home estúdios, abrigando ensaios e gravações. Somam-se dois outros surgidos na década de 1950: o estúdio Rolanton, o primeiro na cidade, e o CAVE (Centro Audiovisual Evangélico) - ambos fora de operação -, e chegamos ao número total de 51 estúdios instalados na cidade desde 1949.
} 
geral um computador e poucos recursos para gravação. ${ }^{11}$

Os serviços que mais se aproximam do trabalho fonográfico na periferia da cidade, e que podem trazer elementos para investigações apuradas, são os fonogramas de propaganda móvel, elaborados por trabalhadores do próprio local. Automóveis e bicicletas percorrem as ruas, e, equipados com caixas de som, realizam a propaganda de anunciantes do entorno, como padarias, lojas de alcance no bairro ou até em toda a cidade, serviços de entrega e divulgação de eventos artísticos ou comunitários.

Para ambos os serviços é necessário que se produza a vinheta ou o comercial, uma demanda não raro atendida pelo próprio prestador do serviço de propaganda móvel, equipe de produção ou ainda por algum conhecido. Essa aproximação com o trabalho fonográfico nos faz questionar sobre a possibilidade de conexão entre os prestadores desse tipo de serviço e o registro sonoro de grupos e artistas locais.

Reafirmamos que possibilidade
técnica não é sinônimo de acessibilidade

\footnotetext{
${ }^{11}$ A situação nos remete ao observado no circuito hip hop na Região de Campinas (ALVES, 2005). Nesse trabalho, constatamos que o circuito de produção de rap, gênero musical da cultura hip hop, se espacializa por meio de relações fundadas no contato pessoal e na solidariedade entre seus agentes. Trata-se de uma produção que conta com quatro home estúdios especializados localizados em Nova Odessa, Hortolândia, Jaguariúna e Valinhos, nenhum deles em Campinas, além da utilização de estúdios de outros gêneros musicais, para a produção em si ou etapas dela. A gravação de rap em casa também vem se tornando uma alternativa para muitos grupos de Campinas e da Região Metropolitana de Campinas - RMC que, utilizando programas de edição sonora em computadores, entre outros dispositivos, conseguem produzir sua própria música.
}

geográfica, ao contrário do proposto pelo discurso tecnocrático. ${ }^{12}$

Por outro lado, a procura pelo registro sonoro nas periferias de Campinas apontou para um espesso circuito em torno das rádios livres, por vezes associadas à difusão de informações ascendentes no circuito sonoro.

Ao que tudo indica, as emissoras livres correspondem em seu conjunto à segunda audiência na cidade. Estima-se que sejam hoje mais de 150 rádios não concessionadas nas periferias da Região Metropolitana de Campinas, demonstrando uma demanda territorial distinta do circuito de FM (Figura 4), bem como dos próprios estúdios fonográficos.

Parte dessas rádios livres fortalece manifestações de cultura popular como a música raiz (a chamada moda de viola) e a folia de reis, entre outros gêneros.

Trata-se de um repertório ligado ao lugar, pois constituído de relações cotidianas nas quais a música e o circuito não são inventados por um outro, mas descobertos por todos, uma construção coletiva acima de tudo.

\footnotetext{
12 Apesar da redução nos custos de instalação dos sistemas técnicos de um estúdio, custa cerca de R\$ $5.000,00$ um conjunto elementar de equipamentos para gravação composto por placa de gravação, um par de monitores de referência e um par de microfones.
} 


\section{Figura 3}

O circuito de produção fonográfica em Campinas (2008): os estúdios e os fornecedores.

$N$
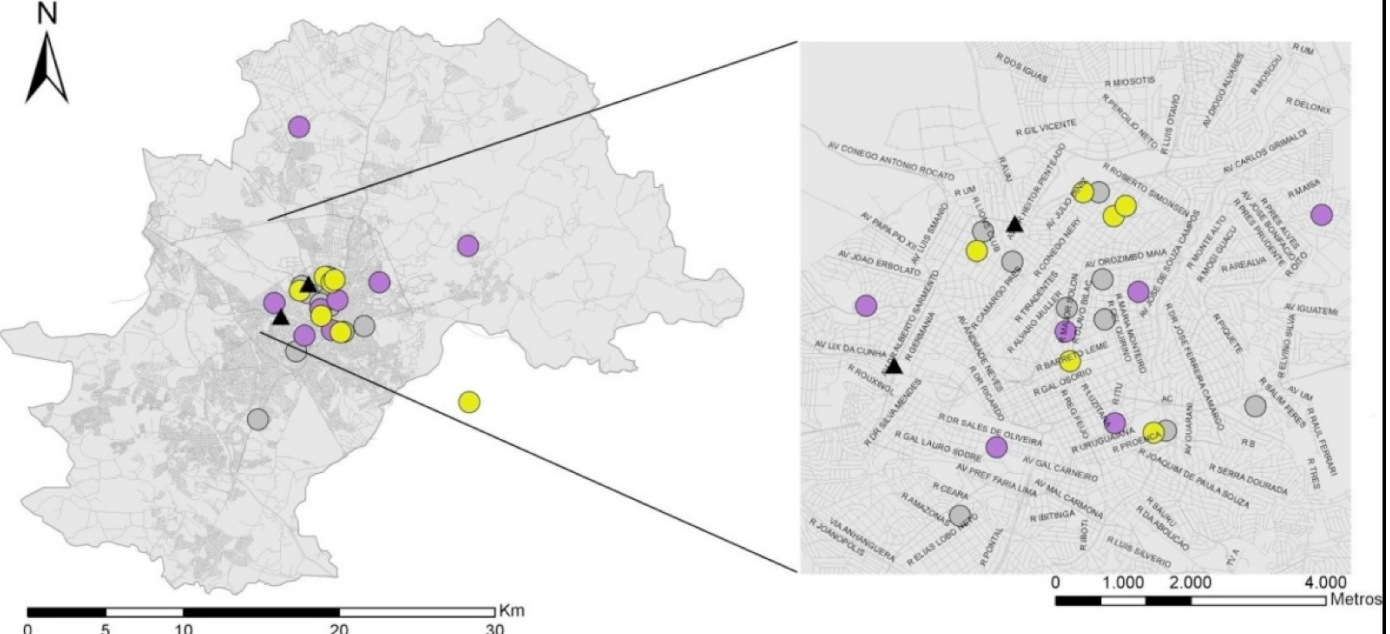

\section{Legenda}

A Fornecedores de Tecnologia de Gravação

Estúdios do Circuito Superior Marginal

Estúdios do Circuito Inferior - Home estúdios

Estúdios do Circuito Inferior - Estúdios Médios

Elaboração: Cristiano Nunes Alves

Figura 4

Emissoras não concessionadas apreendidas na Região de Campinas (2003-2008)

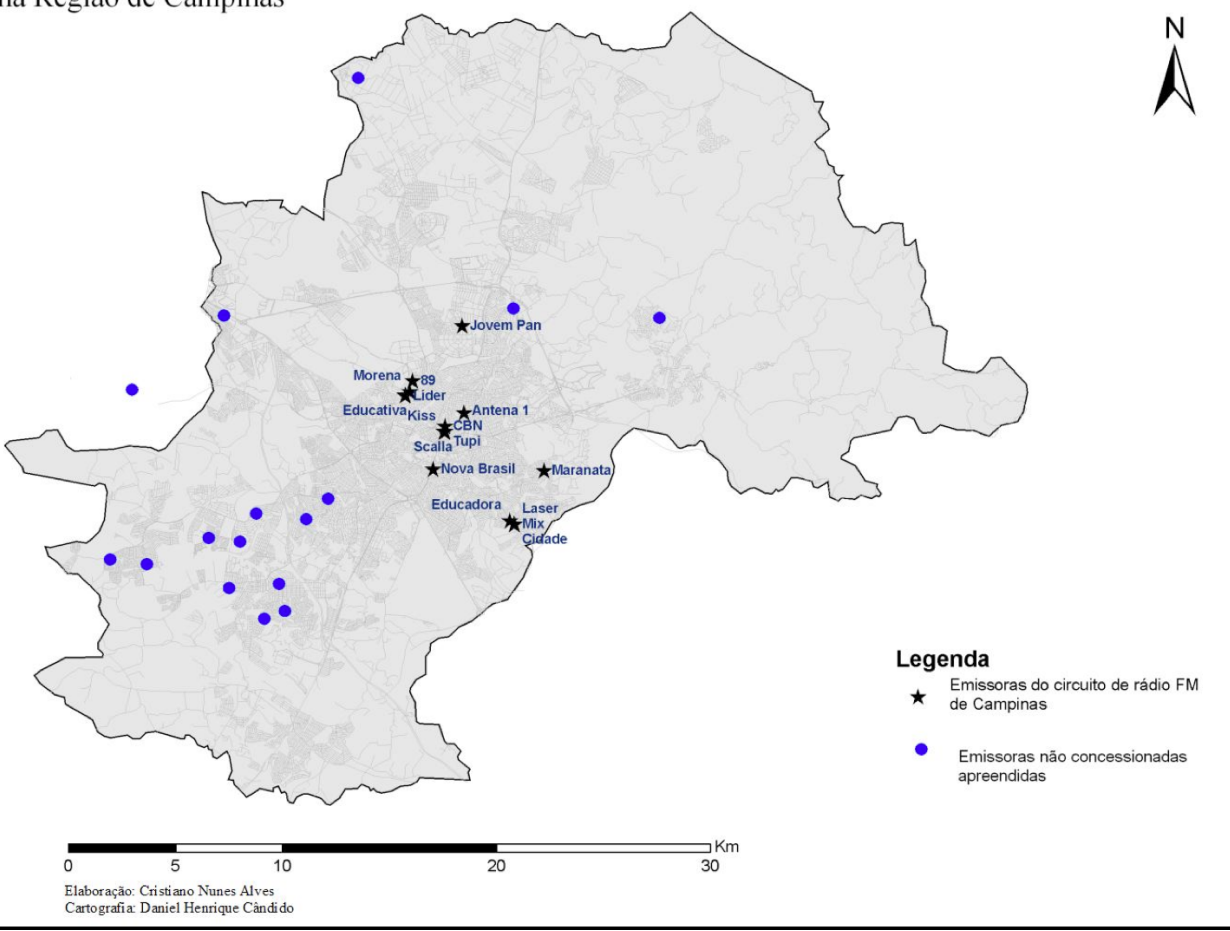


Por outro lado, a diluição do gênero de música raiz, resulta, entre outros, no "sertanejo classe A", repertório de emissoras campineiras concessionadas como a Laser, Tupi e Líder: um golpe na autoestima caipira, confundida por valores que não são os seus, afirmam os militantes comunicacionais da cidade. $^{13}$

Consideramos esses sotaques locais e contestatórios, vemos a possibilidade de união entre a informação e o cotidiano, ponto de partida dos saberes na espessura de densidades comunicacionais nos lugares. Um tipo de conhecimento do mundo a partir dos microcircuitos em permanente mutação do circuito sonoro, mas que carece de maior amarração.

\section{Os circuitos da economia urbana: uma proposta de tipologia para os estúdios fonográficos em Campinas}

A partir do campo de informação primária, sistematizamos o inventário dos estúdios fonográficos em Campinas: os fixos em que a música se torna um registro pronto para o rádio e qualquer outro veículo de transmissão esquizofônico. Nos Quadros 3 e 4, apresentamos uma tipologia para os estúdios da cidade a partir da teoria dos

\footnotetext{
13 Em outros casos a inclusão de um repertório diferenciado na programação das rádios livres não é mais ampla pelo fato da produção alternativa não ser acessível a tais emissoras, algo que tem sido minimizado pelo uso da internet: os CDs caros e os genéricos, em sua grande maioria, representam um repertório padrão. Para quem opera essas rádios o repertório é composto por discos de conhecidos, coleções pessoais e mais um ou outro título. Um dos problemas, portanto, é que as comunitárias e os selos menores não se comunicam, exceção feita a alguns selos produtores de rap.
}

circuitos da economia urbana desenvolvida por Santos (1979). ${ }^{14}$

$$
\text { Almejamos desse modo a }
$$
caracterização da empresa do registro sonoro em Campinas: seus fixos e fluxos, as mensagens e os trabalhos que podem ser produzidos em virtude do campo de informação (PRED, 1979) repercutido pelo conjunto dos prestadores de serviços fonográficos da cidade.Trata-se de uma abordagem da informação e do consumo, duas variáveis relacionadas à ação na escala global, elaboradas no centro do sistema mundo e cuja difusão se amplia nos últimos decênios nos países periféricos. Subsidiados por essa teoria lançamos mão de uma análise tratando do circuito fonográfico, seus agentes, contatos e mediações técnicas, um esforço necessário no delineamento do mercado do circuito sonoro. A pulverização dos estúdios em diversas e menores estruturas físicas, em virtude do barateamento da tecnologia ou incubação do sistema aberto, ocorreu antes que Campinas e seu entorno tivesse criado demanda para ativar o serviço de um grande estúdio ou ainda abrigar uma empresa de prensagem de discos, entre outros serviços. São Paulo permaneceu polarizando a grande produção e, ainda hoje, parte do que é produzido nos estúdios de Campinas recebe tratamento de áudio na capital, entre outros serviços técnicos.

\footnotetext{
14 De acordo com Santos (1979; 1994), circuitos superiores e inferiores da economia se movimentam conjuntamente na cidade, ambos resultado da incompleta modernização tecnológica. Todavia, enquanto o primeiro circuito é decorrência direta "dos progressos tecnológicos e das pessoas que se beneficiam deles" (SANTOS, 1979, p. 29), o segundo é um resultado indireto dos mesmos progressos, que compreende material e organização residuais ao processo.
} 
A tipologia indica que temos em Campinas estúdios do circuito superior marginal e estúdios do circuito inferior, parcela esta que compreende os estúdios médios e os home estúdios. O circuito superior marginal, segundo a proposta de Santos (1979, p. 80), é "constituído de formas de produção menos modernas do ponto de vista tecnológico e organizacional", em relação ao circuito superior propriamente dito. Para o autor este circuito seria a repercussão espacial da sobrevivência de uma modernidade inacabada, ou a implicação de demandas não fortes o suficiente para criar "atividades totalmente modernas" (SANTOS, 1979, p. 80). Esse panorama resultaria num duplo caráter ao circuito superior marginal: residual e emergente, este segundo caráter sendo observado nas cidades intermediárias, caso de Campinas.

Hoje, oito estúdios integram-se ao circuito superior marginal. Nesse grupo, observa-se uma maior espessura técnico-informacional envolvida. Os estúdios do circuito superior marginal operam com softwares de alta tecnologia e valor agregado.
Nessa camada do circuito, temos estúdios que fazem a conexão direta com as majors, produzem para selos-gravadoras, em média por preços em torno de $\mathrm{R} \$ 100,00$ a hora de trabalho, com descontos para artistas independentes. Nos estúdios do circuito superior marginal, cada estúdio disponibiliza uma maior gama de serviços.

Verifica-se uma maior rigidez no procedimento de trabalho nos estúdios do circuito superior marginal: o artista recebe uma planilha com toda a seqüência de trabalho. Os produtores em geral são músicos ou publicitários. Não raro produtores ligados às grandes empresas do setor fonográfico trabalham nos estúdios do circuito superior marginal. Neste grupo, a propaganda é preponderante e a gravação musical na maioria dos casos não é o foco do estúdio.

No que se refere ao circuito inferior, os estúdios se dividem em porte médio e home estúdios (Quadros 2 e 3). 


\section{Quadro 2}

\begin{tabular}{|c|c|c|c|c|c|c|c|c|}
\hline \multicolumn{9}{|c|}{ QUADRO SINTTESE } \\
\hline \multicolumn{7}{|c|}{ Formas e funções - fixos e sistemas técnicos } & \multicolumn{2}{|c|}{$\begin{array}{c}\text { Fluxos - produtos, serviços } \\
\text { Trabalhos e contatos (clientes e demais articulaçôes) }\end{array}$} \\
\hline \begin{tabular}{|c|} 
Tipologia \\
no \\
circuito
\end{tabular} & Estúdio & $\begin{array}{l}\text { Irrcio dos } \\
\text { trraballos }\end{array}$ & Produtor & $\begin{array}{c}\text { Localização } \\
\text { (bairro) }\end{array}$ & $\begin{array}{l}\text { Estrutura fisica } \\
\text { (prédio/ sala de gravaçẫo de } \\
\text { áudio e video) }\end{array}$ & 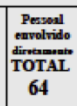 & $\begin{array}{c}\text { Música } \\
\text { (custo de produçâo/gênero/rótulo/artistas) }\end{array}$ & $\begin{array}{l}\text { Video e fonograma publicitírio } \\
\text { (videos promocionais e institucionais/ fonogramas: } \\
\text { trilhas, jingles, spots e vinhetas) }\end{array}$ \\
\hline \multirow{7}{*}{$\begin{array}{l}\text { Circuito } \\
\text { Superior } \\
\text { Marginal }\end{array}$} & BARTHMANNS & 1959 & $\begin{array}{l}\text { Osvaldo } \\
\text { Barthmanns }\end{array}$ & $\begin{array}{l}\text { Jardim } \\
\text { Chapadão }\end{array}$ & $\begin{array}{l}\text { Prédio anexo a casa do } \\
\text { produtor/ uma sala de vídeo e } \\
\text { outra de áudio. }\end{array}$ & 2 & $\begin{array}{l}\text { Trabalho } \\
\text { - Embora não seja o foco atualmente, trata-se de um estúdio com } \\
\text { extensa produção musical, desde bandas a música erudita. } \\
\text { - Custo: } 100,00 \mathrm{R} \$ \text { por Hora. } \\
\text { Contatos } \\
\text { - Proximidade com Dimas e Sr. Henrique Oliveira. }\end{array}$ & $\begin{array}{l}\text { Trabalho } \\
\text { - Video é o foco atual do estúdio. } \\
\text { - Produção de fonogramas publicitánios } \\
\text { - Produção de programas para a sénie Casa Fantástica, } \\
\text { disponiveis no canal de TV infantil Kidschannel. } \\
\text { Contatos } \\
\text { - Grandes meios de informação: fonogramas publicitánios } \\
\text { para a Rádio Transamérica FM e TV Cultura, entre } \\
\text { outros. } \\
\text { - Clientes: D'Paschoal, 3M, Bosch, entre outros. } \\
\text { - Parcerias com Fábio Vidal Ramos, conhecido } \\
\text { personagem do rádio da região. }\end{array}$ \\
\hline & DO SAPO & 1974 & Sapo & $\begin{array}{l}\text { Vila Santana, } \\
\text { Valinhos-SP }\end{array}$ & $\begin{array}{l}\text { Estúdio em prédio próprio/ } \\
\text { ampla sala de áudio. }\end{array}$ & 3 & $\begin{array}{l}\text { Trabalho } \\
\text { - Produção de diversos gêneros, do pop ao sertanejo: "Aqui não } \\
\text { temos preconceito" afirmou-nos o produtor Sapo*, músico da } \\
\text { Banda do Brejo e fundador do estúdio. } \\
\text { - Custo: cada faixa sai de } 800,00 \mathrm{RS} \text { a } 1.500,00 \mathrm{R} \$ \text { reais com a } \\
\text { inserção de instrumentos de sopro, um time de cordas, entre } \\
\text { outros. } \\
\text { - Contato com produtores difundidos pela grande mídia. }\end{array}$ & $\begin{array}{l}\text { Trabalho } \\
\text { - Nâo trabalha com vídeo } \\
\text { - Extensa produção de fonogramas publicitários, } \\
\text { especialmente jingles: "um jungle é uma coisa séria, o } \\
\text { texto falado não tem o mesmo alcance" sentencia Sapo. } \\
\text { entatos } \\
\text { - Clientes: Sanasa, Manolo, Unilever, entre outros. } \\
\text { - Grandes meios de informação: elaboração de } \\
\text { fonogramas publicitários para EPTV, TVB, erádios } \\
\text { Cidade FM, Educadora FMe Central AM, entre outros. }\end{array}$ \\
\hline & DIMAS & 1980 & $\begin{array}{l}\text { Dimas } \\
\text { d'Amico }\end{array}$ & Centro & $\begin{array}{l}\text { Estúdio em prédio próprio/ três } \\
\text { salas de áudio. }\end{array}$ & 7 & $\begin{array}{l}\text { Trabalho/contatos: } \\
\text { - Dimas foi divulgador de gravadoras, entre as quais a RGE. } \\
\text { - Produção especialmente de MPB e música erudita. } \\
\text { - A música é produzida esporadicamente no estúdio, como no } \\
\text { caso do Disco do Grupo Bons Tempos. } \\
\text { - Até 2005 o estúdio era sede da Disciplina "Prática de } \\
\text { Estúdio", do curso de graduação em música da Unicamp. }\end{array}$ & $\begin{array}{l}\text { Trabalho } \\
\text { - Não trabalha com video } \\
\text { - Extensa produção de fonogramas publicitánios, o foco } \\
\text { do estúdio. } \\
\text { e Contatos } \\
\text { - Grandes meios de informação: elaboração de vinhetas } \\
\text { para as emissoras de FM Educadora, Morena e Eldorado } \\
\text { (São Paulo-SP). }\end{array}$ \\
\hline & MAIS MAIS & $198 ?$ & André Mais & $\begin{array}{c}\text { Nova } \\
\text { Campinas }\end{array}$ & $\begin{array}{l}\text { Estudio em prédio próprio. } \\
\text { ampla sala de gravaçâo. }\end{array}$ & $\begin{array}{c}\text { sem } \\
\text { insemaghato }\end{array}$ & $\begin{array}{l}\text { Trabalho/contatos: } \\
\text { - Produção de artistas de massa como a dupla sertaneja } \\
\text { Chitãozinho e Xororó. } \\
\text { - Rendimento com direitos conexos advindos da venda dessa } \\
\text { produçães } \\
\text { - Três prêmios Grammy (inserção no maistream) } \\
\end{array}$ & Não atua na área \\
\hline & MSG & 1988 & $\begin{array}{l}\text { Marcelo } \\
\text { Giorgetti }\end{array}$ & Taquaral & $\begin{array}{l}\text { Estúdio em prédio próprio/duas } \\
\text { salas de áudio. }\end{array}$ & 9 & Trabalho esporádico com música & $\begin{array}{l}\text { Trabalho } \\
\text { - Produção de vídeos e fonogramas publicitários em geral } \\
\\
\text { Contatos/clientes } \\
\text { - Decatlhon Materiais Esportivos, Shopping Galleria, } \\
\text { Pizza Hut, FIAT, entre outros. }\end{array}$ \\
\hline & CRISTAL & 1989 & Paulo & Taquaral & $\begin{array}{l}\text { Prédio anexo a casa do } \\
\text { produtor/ uma sala de áudio e } \\
\text { outra de vídeo. }\end{array}$ & 2 & $\begin{array}{l}\text { Trabalho } \\
\text { - Custo: o disco sai a partir de } 50 \text { mil reais para uma } \\
\text { gravadora. } \\
\text { Contatos } \\
\text { - Já trabalhou com diveros gêneros, inclusive com grupos de } \\
\text { rap da região, entre os quais DLM, Sistema Negro e Face da } \\
\text { Morte. } \\
\text { - Hoje trabalha com o "rap pop" de Benê, ex-inegrante do } \\
\text { gupo Sistema Negro. } \\
\text { - Atualmente produz música apenas para conhecidos, como o } \\
\text { grupo Musicaria. } \\
\text { - Grandes meios de informação: realizou ainda produções para } \\
\text { a Abril Music. }\end{array}$ & $\begin{array}{l}\text { Trabalho } \\
\text { - Produção de videos promocionais e fonogramas } \\
\text { publicitarios. } \\
\text { Contatos com grandes meios de informação: } \\
\text { - Antena } 1 \mathrm{FM} \text {. } \\
\text { - Ganhou no ano de } 2007 \text { o prêmio de melhor } \\
\text { propaganda escolhida pela APP (Associação Paulista de } \\
\text { Propaganda), com o jingle da Caninha } 51 \text { no nordeste. } \\
\end{array}$ \\
\hline & & & & & & & $\begin{array}{l}\text { Trabalho } \\
\text { - Custos: } 92 \text { reais por hora. Pacote com descontos para músicos } \\
\text { independentes (artistas não intermediados por selos). Num plano }\end{array}$ & \begin{tabular}{l|l} 
s & Trabalho \\
- Não trabalha com vídeo
\end{tabular} \\
\hline
\end{tabular}




\section{Quadro 3}

\begin{tabular}{|c|c|c|c|c|c|c|c|c|}
\hline \multicolumn{7}{|c|}{ Formas e funções - fixos e sistemas técnicos } & \multicolumn{2}{|c|}{$\begin{array}{c}\text { Fluxos - produtos, serviços } \\
\text { Trabalhos e contatos (clientes e demais articulações) }\end{array}$} \\
\hline $\begin{array}{c}\text { Tipologia } \\
\text { no } \\
\text { circuito }\end{array}$ & Estúdio & 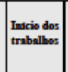 & Produtor & $\begin{array}{c}\text { Loealizacào } \\
\text { (bairro) }\end{array}$ & $\begin{array}{l}\text { Estrutura fisica } \\
\text { (prédio/ sala de gravaçâo de } \\
\text { áudio e video) }\end{array}$ & 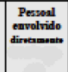 & $\begin{array}{c}\text { Música } \\
\text { (custo de produçầ/gênero/rótulo/artistas) }\end{array}$ & $\begin{array}{l}\text { Video e fonograma publicitário } \\
\text { (videos promocionais e institucionais/ fonogramas: } \\
\text { trilhas, jingles, spots e vinhetas) }\end{array}$ \\
\hline \multirow{9}{*}{\begin{tabular}{|l|} 
Circuito \\
Inferior \\
Estidios \\
Médios
\end{tabular}} & HENRISON & 1952 & $\begin{array}{l}\text { Henrique de } \\
\text { Oliveira }\end{array}$ & Cambuí & $\begin{array}{l}\text { Estúdio em prédio anexo a casa } \\
\text { do produtor }\end{array}$ & 1 & \multicolumn{2}{|c|}{ - Experiências audiovisuais pioneiras em Campinas } \\
\hline & LPC & 1976 & Jaider & $\underset{\text { Chapadão }}{\text { Jardim }}$ & $\begin{array}{l}\text { Estúdio em prédio próprio/ uma } \\
\text { sala de vídeo e outra de áudio }\end{array}$ & 6 & $\begin{array}{l}\text { Parceria entre a Igreja Presbiteriana do Brasil e a Igreja Cristã } \\
\text { Reformada da América do Norte. } \\
\text { - Produção de música gospel } \\
\text { - Relação com estúdio HS }\end{array}$ & $\begin{array}{l}\text { Contatos } \\
\text { - Produz vídeos institucionais para a igreja } \\
\text { presbiteriana. } \\
\text { - Produz conteúdo para programas de emissoras gospel } \\
\text { de diversas cidades como Adamantina, Bebedouro, } \\
\text { Taubaté e Assis, entre outras. }\end{array}$ \\
\hline & NM & 1989 & $\begin{array}{l}\text { Stevan } \\
\text { Datolo }\end{array}$ & Cambuí & $\begin{array}{l}\text { Estúdio em prédio próprio/ sala } \\
\text { de video e áudio }\end{array}$ & 3 & Grava apenas trabalhos de conhecidos. & Foco do estúdio \\
\hline & SM & 1991 & \begin{tabular}{|l|} 
Antônio \\
Carlos \\
e Leonardo
\end{tabular} & Vila Santana & $\begin{array}{l}\text { Estúdio em prédio próprio/uma } \\
\text { sala de gravação de áudio }\end{array}$ & 2 & \begin{tabular}{|l|} 
Trabalho \\
- Gênero: produz o popularesco (sertanejo e pagode) e às vezes \\
rap ou pop rock. \\
- Produção de cerca trinta discos simultaneamente. \\
- Custos: $55,00 \mathrm{RS}$ por hora de gravacano/A pantir de $3.000,00 \mathrm{RS}$ \\
por uma matriz de disco/ $3.000,00 \mathrm{RS}$ cada mil cópias. \\
Contatos: \\
- Clientes de classe média baixa. \\
- Rádios não concessionadas \\
- Rede Familia e abertura para divulgação de artistas.
\end{tabular} & Não atua nesta área \\
\hline & GENES & 1993 & $\begin{array}{l}\text { Crysogenes } \\
\text { Cebolinha }\end{array}$ & $\underset{\text { José }}{\text { Jardim São }}$ & $\begin{array}{l}\text { Prédio anexo a casa do } \\
\text { produtor/uma sala de áudio }\end{array}$ & 3 & \begin{tabular}{|l|} 
Trabalho - ESTÚDIO DO SELO GENES \\
- Gênero: produz o popularesco (sertanejo, evangélico, pagode) \\
e às vezes gospel ou pop rock. \\
Custos: produção a partir de $10.000,00$ RS. Com acréscimos de \\
instrumentos como violinos chega até $30.000,00$ RS. \\
Contatos: \\
- Clientes de classe média baixa. \\
- Rádios não concessionadas \\
- Antes gravava no estúdio Mais Mais
\end{tabular} & Não atua nesta área \\
\hline & BASEMENT & 1997 & Tarsa & $\begin{array}{c}\text { Nova } \\
\text { Campinas }\end{array}$ & $\begin{array}{l}\text { Prédio anexo a residência do } \\
\text { produtor/ uma sala de áudio }\end{array}$ & 1 & $\begin{array}{l}\text { Custos: cada faixa pode custar a partir de } 100,00 \mathrm{RS} \text {. } \\
\text { Contatos: } \\
\text { - Produziu mais de } 300 \text { bandas da cena independente de } \\
\text { Campinas e região, tomando-se referência regional. }\end{array}$ & Não atua nesta área \\
\hline & NOSOTROS & 2001 & $\begin{array}{l}\text { Tarsis Conti } \\
\text { e Roger }\end{array} \mid$ & Bosque & $\begin{array}{l}\text { Estúdio em prédio próprio/ } \\
\text { duas salas de áudio }\end{array}$ & 2 & $\begin{array}{l}\text { - Utilizado para gravação e ensaios } \\
\text { - Até } 2005 \text { existia como home studio } \\
\text { - No estúdio funciona ainda uma escola de música. }\end{array}$ & Não atua nesta área \\
\hline & LOUDNESS & 2003 & $\begin{array}{l}\text { Luis } \\
\text { Fernando }\end{array}$ & & Estúdio móvel & Sem & $\begin{array}{l}\text { - A empresa há } 30 \text { anos oferece serviços de sonorização de } \\
\text { eventos musicais e } 5 \text { há cinco anos grava-os. } \\
\text { - Produziu eventos para artistas como Amaldo Antunes, } \\
\text { Barbatuques, Elba Ramalho, Elza Soares, Mutantes, entre } \\
\text { outros. }\end{array}$ & Não atua nesta área \\
\hline & GRANJA & 2004 & $\begin{array}{l}\text { Luis Granja } \\
\text { e Tarsa }\end{array}$ & Cambuí & $\begin{array}{l}\text { Estúdio em prédio próprio/ } \\
\text { duas salas de áudio }\end{array}$ & 2 & \begin{tabular}{|l|} 
Trabalho \\
- Produção de bandas de Campinas e região. \\
- Utilizado também para ensaios. \\
- Custas: $65,00 \mathrm{RS}$ por hora. Opcão por $60,00 \mathrm{RS}$ a hora com \\
quatro músicas gravadas em 16 canais, mixadas e masterizadas \\
em três horas \\
Contatos: \\
- Proximidade com a equipe da $89 \mathrm{FM}$ e com o estúdio Kidman
\end{tabular} & Não atua nesta área \\
\hline
\end{tabular}

Dos dez estúdios médios, sete surgiram depois de 1990, enquanto, dos nove home estúdios, apenas um, o Divulgasom, surgiu antes, em 1968. Os nove home estúdios envolvem diretamente 13 pessoas, enquanto os outros 17 estúdios, entre médios e do circuito superior marginal envolvem 51 pessoas. Um menor número de pessoas envolvidas, em proporção, por estúdio, observa-se nos home studios, cinco deles nas casas dos produtores, com cômodos transformados, refuncionalizando um quarto ou uma sala, por exemplo. Um maior volume de gravações de música ocorre entre os estúdios do circuito inferior e uma conseqüente aproximação com um grande número de artistas e bandas de diversos lugares.

Em razão da flexibilidade nas relações de trabalho - lembramos que a maior parte do circuito é movimentada por trabalhadores eventuais, os chamados free-lancers - tornase difícil saber exatamente o número de pessoas envolvidas em torno do registro musical.

Com relação aos selos de gravação, estes se colocam na condição de agentes do circuito superior marginal, na medida em que assumem o papel de conexão com grandes 
canais de distribuição e divulgação. Trata-se de uma hipótese a ser considerada. Inventariamos o funcionamento de dez selos na região de Campinas. Estabelecendo contatos a partir de seus escritórios, os selos oferecem serviços de assessoria fonográfica, pré-masterização, arte final, editoração musical, entre outros.

\section{Considerações finais}

A situação estudada indica que apenas na década de 1990 define-se mais nitidamente o processo de influência dos grandes meios de informação sobre o circuito sonoro, adensado durante o processo. A proposta de um estudo sobre a rádio $\mathrm{FM}$ e a produção sonora ou fonográfica em Campinas apontou o elo entre os dois circuitos, basicamente por meio da propaganda. As emissoras concessionadas e os estúdios fonográficos de maior porte concorrem por esse tipo de serviço.

Destaca-se no inventário da produção fonográfica a concentração dos estúdios em bairros de classe média alta, grosso modo nos arredores do Centro, o que significa dizer que essa produção representa pequena parcela da cidade de Campinas. Mesmo com o barateamento dos custos na instalação de um estúdio fonográfico, trata-se de um

investimento inviável para a grande maioria dos trabalhadores culturais da cidade. Por outro lado, as rádios livres exprimem a demanda informacional oposta, das periferias da cidade, demonstrando certa cisão territorial.

Em algumas situações estudadas, a pesquisa nos indicou a existência de elementos comunicativos essencialmente residuais, cujos aspectos são: programação das rádios livres, proximidade dos contatos entre agentes, bares e estúdios que difundem conteúdos informacionais ascendentes participando, ou não, de um mercado de bens culturais. Nestes casos o circuito sonoro é visto mais como circuito produtor de arte do que como produto à venda; mais fruto de trabalho do que resultado de empregos. Constituir-se-ia um saber sonoro Baseado mais nas práticas e nas ações do que num moderno sistema de objetos. Tais densidades do cotidiano são potencialmente condutores da construção de algo novo, de importância qualitativa e não utilitarista ou numérica.

Trata-se de uma agenda de pesquisa a ser mais bem desenvolvida. O que se sabe é que as formas-conteúdo da cultura popular e a postura de vanguarda confrontam visceralmente as esferas de controle a partir de concepções estéticas que ecoarão na geografia dos lugares, no seu mercado e na sua política.

\section{Referências bibliográficas}

\author{
ALVES, C. N. O circuito hip hop na Região \\ Metropolitana de Campinas: para \\ que o território e a arte digam algo \\ sobre nossas vidas. Monografia \\ (Conclusão de Curso de Geografia) - \\ Instituto de Geografia, Universidade \\ Estadual de Campinas, Campinas, \\ 2005.
}

\author{
ALVES, C. N. O circuito sonoro: \\ radiodifusão $\mathrm{FM}$ e produção \\ fonográfica em Campinas-SP. \\ Dissertação (Mestrado em Geografia) \\ - Instituto de Geografia, Universidade \\ Estadual de Campinas, Campinas, \\ 2008.
}


AMAYO, G. C. Rádio público na cidade de São Paulo. Tese (Doutorado em Comunicação) - Escola de Comunicações e Artes, Universidade de São Paulo. São Paulo, 1992.

BECKER, H. Uma teoria da ação coletiva. Rio de Janeiro: Zahar, 1977.

BRENNETOT, A. Des festival pour animer les territoires. Annales de Géographie, n. 635,2004 , p. 29-50.

CALDAS, W. Luz néon: canção e cultura na cidade. São Paulo: SESC, 1995.

CARNEY. G. O. Geography of Music: Inventory and Prospect. Journal of Cultural Geography, n. 10, 1990, p. 35-48.

CHAUDOIR, P. Spectacles, fêtes et sons urbains. Géocarrefour, n. 78, 2003, p. 167-172.

CLAIRE, G. Géographie et musique: état des lieux. Une proposition de synthèse. Geógraphie et Cultures, n. 59, 2006, p. 7-26).

FRIEDMANN, G. Sete estudos sobre o homem e a técnica. São Paulo: Difel, 1968.

FRITH, S. Art vs Technology: the Strange Case of Popular Music. In: FRITH, S. (Org, ). Critical concepts in media and cultural studies, v. II: The rock era. London: Routledge, 2004. p. 107-122.

GEIGER, P. P. Evolução da rede urbana brasileira. Rio de Janeiro: Inep, 1963.

GORZ, A. O imaterial: conhecimento, valor e capital. São Paulo: Annablume, 2005.

HÄGERSTRAND, T. Innovation diffusion as a spatial process. Chicago/London: The University of Chicago Press, 1967.

HARVEY, D. Condição pós-moderna. São Paulo: Loyola, 1992.

HARVEY, D. A arte de lucrar. In: MORAES, D. (Org.). Por uma outra comunicação: mídia, mundialização cultural e poder. Rio de Janeiro: Record, 2003. p. 139-171.
HARVEY, D. Espaços de esperança. São Paulo: Loyola, 2006.

LEFEBVRE, H. O direito à cidade. São Paulo: Documentos, 1969.

LUCCA, S. de. O produto musical nas rádios brasileiras e aspectos de sua influência: um panorama atual paulistano. Dissertação (Mestrado em Comunicação) - Escola de Comunicações e Artes, Universidade de São Paulo. São Paulo, 2002.

MARIANO, J. História da imprensa em Campinas. Campinas: Massaioli, 1972.

MATTELART, A. As multinacionais da cultura. Rio de Janeiro: Civilização Brasileira, 1976.

MORELLI, R. L. Arrogantes, anônimos, subversivos: interpretando o acordo e a discórdia na tradição autoral brasileira. Tese (Doutorado em Antropologia) - Instituto de Filosofia e Ciências Humanas, Universidade Estadual de Campinas, Campinas, 1998.

NETO, N. T. Enterrado vivo. São Paulo: Editora Unesp, 2004.

ORTIZ, R. Um outro território: ensaios sobre a mundialização. São Paulo: Olho d'Água, 2001.

ORTRIWANO, G. S. A informação no rádio: os grupos de poder e a determinação dos conteúdos. São Paulo: Summus, 1985.

PAILHÉ, J. Le jazz, mondialisation et territorialité. Mappemonde, n. 51, 1998, p. 38-43.

PRED, A. Sistemas de cidades: economia adiantada, crescimento passado, processos presentes e opções de desenvolvimento futuro. Rio de Janeiro: Zahar, 1979.

RAFFESTIN, C. Por uma geografia do poder. São Paulo: Ática, 1993.

RAIBAUD, Y. Les fêtes musicales: experiénce de la ville et performativité. Geógraphie et Cultures, n. 59, 2006, p. 43-56. 
ROMAGNAN, J. La musique: un terrain nouveau pour les géographes. Géographie et Cultures, n. 36, 2000, p. 107-126.

SALGADO, Á. Radiodifusão fator social. Cultura Política, Rio de Janeiro, 1941, p. 79-93.

SANTOS, M. O espaço dividido: os dois circuitos da economia urbana dos países subdesenvolvidos. Rio de Janeiro: Francisco Alves, 1979.

. Técnica, espaço e tempo. São Paulo: Hucitec, 1994a.

. A urbanização brasileira. São Paulo: Hucitec, 1994 b.

A natureza do espaço: técnica e tempo, razão e emoção. São Paulo: Hucitec, 1997.

SANTOS, M.; SILVEIRA, M. L. O Brasil: território e sociedade no início do século XXI. Rio de Janeiro: Record, 2001.

SCHAFER, R. M. A afinação do mundo uma exploração pioneira pela história passada e pelo atual estado do mais negligenciado aspecto do nosso ambiente: a paisagem sonora. São Paulo: Unesp, 1997[1977].

SILVEIRA, M. L. Uma situação geográfica: do método à metodologia. Território, ano IV, n. 6, 1999, p. 21-27.

SODRÉ, M. A comunicação do grotesco: um ensaio sobre a cultura de massas no Brasil. Petrópolis: Vozes, 1976.

SODRÉ, M. Reinventando a cultura: a comunicação e seus produtos. Rio de Janeiro: Vozes, 1999.

VICENTE, E. A música popular e as novas tecnologias de produção musicais: uma análise do impacto das tecnologias digitais no campo da produção da canção popular de massas. Dissertação (Mestrado em Sociologia) - Instituto de Filosofia e Ciências Humanas, Universidade Estadual de Campinas, Campinas, 1996.

VICENTE, E. Música e disco no Brasil: a trajetória da indústria nas décadas de 80 e 90 . Tese (Doutorado em Comunicação) - Escola de Comunicações e Artes, Universidade de São Paulo. São Paulo, 2000. 